\title{
HIV-1 Drug Resistance Genotyping in Resource Limited Settings: Current and Future Perspectives in Sequencing Technologies
}

\author{
Sontaga Manyana ${ }^{1, *(\mathbb{D})}$, Lilishia Gounder ${ }^{1} \mathbb{D}$, Melendhran Pillay ${ }^{1}$, Justen Manasa ${ }^{2} \mathbb{D}$, Kogieleum Naidoo $^{3,4}$ \\ and Benjamin Chimukangara 1,3
}

1 National Health Laboratory Service, Department of Virology, School of Laboratory Medicine and Medical Sciences, University of KwaZulu-Natal, Durban 4058, South Africa; Gounder@ukzn.ac.za (L.G.); melendhra.pillay@nhls.ac.za (M.P.); ChimukangaraB@ukzn.ac.za (B.C.)

2 Department of Laboratory Medicine and Investigative Sciences, Faculty of Medicine and Health Sciences, University of Zimbabwe, Harare, Zimbabwe; jmanasa@uz.edu.zw

3 Centre for the AIDS Programme of Research in South Africa (CAPRISA), Durban 4013, South Africa; Kogie.Naidoo@caprisa.org

4 South African Medical Research Council (SAMRC), CAPRISA HIV-TB Pathogenesis and Treatment Research Unit, Durban 4013, South Africa

* Correspondence: 221116823@stu.ukzn.ac.za; Tel.: +27-(0)3-1240-2794

Citation: Manyana, S.; Gounder, L.; Pillay, M.; Manasa, J.; Naidoo, K.;

Chimukangara, B. HIV-1 Drug

Resistance Genotyping in Resource Limited Settings: Current and Future Perspectives in Sequencing Technologies. Viruses 2021, 13, 1125. https://doi.org/10.3390/v13061125

Academic Editor: Vinay Pathak

Received: 10 May 2021

Accepted: 31 May 2021

Published: 11 June 2021

Publisher's Note: MDPI stays neutral with regard to jurisdictional claims in published maps and institutional affiliations.

Copyright: (c) 2021 by the authors. Licensee MDPI, Basel, Switzerland. This article is an open access article distributed under the terms and conditions of the Creative Commons Attribution (CC BY) license (https:/ / creativecommons.org/licenses/by/ $4.0 /)$.

\begin{abstract}
Affordable, sensitive, and scalable technologies are needed for monitoring antiretroviral treatment (ART) success with the goal of eradicating HIV-1 infection. This review discusses use of Sanger sequencing and next generation sequencing (NGS) methods for HIV-1 drug resistance (HIVDR) genotyping, focusing on their use in resource limited settings (RLS). Sanger sequencing remains the gold-standard method for detecting HIVDR mutations of clinical relevance but is mainly limited by high sequencing costs and low-throughput. NGS is becoming a more common sequencing method, with the ability to detect low-abundance drug-resistant variants and reduce per sample costs through sample pooling and massive parallel sequencing. However, use of NGS in RLS is mainly limited by infrastructure costs. Given these shortcomings, our review discusses sequencing technologies for HIVDR genotyping, focusing on common in-house and commercial assays, challenges with Sanger sequencing in keeping up with changes in HIV-1 treatment programs, as well as challenges with NGS that limit its implementation in RLS and in clinical diagnostics. We further discuss knowledge gaps and offer recommendations on how to overcome existing barriers for implementing HIVDR genotyping in RLS, to make informed clinical decisions that improve quality of life for people living with HIV.
\end{abstract}

Keywords: HIV-1 drug resistance; Sanger sequencing; next generation sequencing; resource limited settings

\section{Introduction}

In an effort to end the HIV epidemic by 2030, the UNAIDS 95-95-95 goals aim to ensure that $95 \%$ of all people living with HIV know their status, 95\% of all people diagnosed receive sustained antiretroviral treatment (ART), and $95 \%$ of all people receiving ART have sustainable viral suppression [1,2]. HIV-1 drug resistance (HIVDR) remains a major threat to achieving these targets, particularly in achieving the third target of $95 \%$ viral suppression [3]. HIVDR genotyping before ART initiation and at ART failure improves effectiveness of subsequent treatment [4,5], but its use in resource limited settings (RLS) is often restricted by costs. Although Sanger sequencing remains the preferred clinical diagnostic method for HIVDR genotyping, next generation sequencing (NGS) methods are becoming more affordable but their use in the therapeutic management of patients on ART is yet to be established [6]. 
Sanger sequencing is a population-based method that uses a di-deoxy chain termination chemistry to generate a single consensus sequence representative of the most common bases at each nucleotide position [7]. This, however, means that Sanger sequencing does not reliably detect mutations that are less represented within the viral pool, also known as low-abundance drug-resistant variants (LA-DRVs) [8,9]. Despite that, HIVDR mutations detected by Sanger sequencing have been shown to predict treatment response, making it a reliable method for use in making clinical decisions [10]. On the other hand, NGS is more sensitive, having the ability to detect LA-DRVs (i.e., viral variants at $<20 \%$ ) [11], and enabling quantitative detection of HIVDR mutations [12]. However, there remains a dearth of knowledge around the clinical significance of LA-DRVs on ART effectiveness [13], although a high concordance with Sanger sequencing has been shown in detection of mutations at $\geq 20 \%$ frequency [6].

NGS also has the ability for massive parallel sequencing of individual input templates, generating incredible amounts of data per sequencing run [11,14]. Given its highthroughput and cost-efficiency through parallel sequencing and sample pooling, NGS is becoming a more common method for HIVDR genotyping [14,15]. In this review, we discuss the available and emerging Sanger sequencing and NGS methods for HIVDR genotyping, highlighting challenges for their use in RLS and for clinical diagnostics.

\section{Overview of Sanger Sequencing and NGS Platforms}

Sanger sequencing platforms have largely been dominated by Applied Biosystems, with instruments ranging from 3100- to 3700-series, as well as the SeqStudio (Applied Biosystems, Tustin, CA, USA) instrument [16]. The ABI 3730xl (Applied Biosystems, Tustin, CA, USA) genetic analyzer is the most robust of these instruments with highthroughput, scalability and flexibility. It can sequence fragments up to $900 \mathrm{bp}$ in a single read and can process 96 reactions simultaneously and continuously for several sequencing plates at a time [17]. However, its throughput is nowhere comparable to NGS, which can produce millions of reads from a single sequencing run [18,19]. Moreover, NGS has several sequencing platforms from different manufacturers such as Illumina (Illumina, CA, USA), Thermo Fisher (Thermo Fisher Scientific, Waltham, MA, USA), Pacific Biosciences (PacBio) (PacBio, CA, USA) and Oxford Nanopore Technologies (ONT) (ONT, Oxford, UK). Illumina uses a sequencing-by-synthesis chemistry and is arguably one of the most widely used NGS platforms, offering flexibility in choice of instruments, with varying read-lengths and sequencing outputs [20]. Considering that HIVDR genotypic testing in RLS is mainly targeted on the HIV-1 pol gene, Illumina's short read sequencing and lower instrument cost make it a front runner for HIVDR genotyping [21]. Table 1 provides a summary of the popular NGS platforms, highlighting their technical differences.

Table 1. Summary of popular NGS platforms.

\begin{tabular}{|c|c|c|c|c|c|c|}
\hline Manufacturer & Platforms & $\begin{array}{l}\text { Instrument } \\
\text { Cost (US\$) }\end{array}$ & Chemistry & $\begin{array}{l}\text { Read Length } \\
\text { (bp) }\end{array}$ & $\begin{array}{l}\text { Maximum } \\
\text { Output (Gb) }\end{array}$ & Error Rate (\%) \\
\hline \multirow{6}{*}{ Illumina } & iSeq 100 & \multirow{6}{*}{$19,900-950,000$} & \multirow{6}{*}{ SBS } & \multirow{6}{*}{$150-300$} & \multirow{6}{*}{$0.3-6000$} & \multirow{6}{*}{0.1} \\
\hline & MiniSeq & & & & & \\
\hline & MiSeq & & & & & \\
\hline & NextSeq & & & & & \\
\hline & HiSeq & & & & & \\
\hline & NovaSeq & & & & & \\
\hline \multirow{3}{*}{ Thermo Fisher } & Ion S5 & \multirow{3}{*}{$60,000-149,000$} & \multirow{3}{*}{$\begin{array}{c}\text { Ion } \\
\text { semiconductor }\end{array}$} & \multirow{3}{*}{$200-400$} & \multirow{3}{*}{$0.08-15$} & \multirow{3}{*}{1} \\
\hline & Ion PGM & & & & & \\
\hline & Ion Proton & & & & & \\
\hline
\end{tabular}


Table 1. Cont.

\begin{tabular}{|c|c|c|c|c|c|c|}
\hline Manufacturer & Platforms & $\begin{array}{l}\text { Instrument } \\
\text { Cost (US\$) }\end{array}$ & Chemistry & $\begin{array}{l}\text { Read Length } \\
\text { (bp) }\end{array}$ & $\begin{array}{l}\text { Maximum } \\
\text { Output (Gb) }\end{array}$ & Error Rate (\%) \\
\hline \multirow{3}{*}{$\begin{array}{c}\text { Pacific } \\
\text { Biosciences }\end{array}$} & Sequel II & \multirow{3}{*}{$350,000-750,000$} & \multirow{3}{*}{ SMRT } & \multirow{3}{*}{60,000} & \multirow{3}{*}{$0.5-10$} & \multirow{3}{*}{13} \\
\hline & Sequel IIe & & & & & \\
\hline & Sequel & & & & & \\
\hline \multirow{3}{*}{$\begin{array}{c}\text { Oxford } \\
\text { Nanopore } \\
\text { Technologies }\end{array}$} & MinIon & \multirow{3}{*}{$1000-25,000$} & \multirow{3}{*}{ Nanopore } & \multirow{3}{*}{$>100,000$} & \multirow{3}{*}{$10-960$} & \multirow{3}{*}{12} \\
\hline & GridION & & & & & \\
\hline & PromethION & & & & & \\
\hline
\end{tabular}

SBS, sequencing-by-synthesis; SMRT, Single Molecule Real-Time; US\$, United States Dollars; bp, base pair; Gb, Gigabase. This table was adapted from the following references [12,22].

\section{Sanger Sequencing and NGS for HIVDR Genotyping}

Several in-house Sanger sequencing assays have been developed over the years for HIVDR genotyping. However, there is currently one commercially available Sanger sequencing assay approved by the US Food and Drug Administration (FDA) for HIVDR genotyping, namely ViroSeq HIV-1 Genotyping kit [23-26]. The kit is relatively expensive, costing approximately US $\$ 380$ per test, making it less affordable for RLS [27]. This makes laboratories resort to developing low-cost in-house assays, and in some cases modifying commercial assays to reduce costs [28]. A personal view by Inzaule et al. previously estimated that the costs of HIVDR genotyping in-house assays range from US $\$ 47.50$ to US\$155, without labor costs [14], although these could vary further depending on costs of procuring laboratory reagents and consumables.

A collaborative partnership between the Southern African Treatment and Resistance Network (SATuRN) and not-for-profit manufacturers (Life Technologies/Centers for Disease Control and Prevention) previously developed a discounted HIVDR genotyping assay that reliably detects mutations in the HIV-1 protease (PR) and reverse transcriptase (RT) genes from plasma and dried blood spot samples by Sanger sequencing [14,29-31]. Such partnerships are essential to validate in-house HIVDR genotyping assays and make them commercially affordable for RLS. Table 2 shows a summary of published in-house HIVDR genotyping assays targeted for use in RLS.

There is currently only one commercially available NGS assay approved by the FDA in November 2019 for clinical HIVDR genotyping, known as the Sentosa SQ HIV-1 Genotyping Assay [12,50]. This is a standardized, semi-automated and novel deep in vitro sequencing assay developed by Vela Diagnostics (Vela-Diagnostics, Humburg, Germany) for sequencing the combined HIV-1 PR, RT and integrase (IN) genes with minimal expertise [51]. The instrument alone costs $\sim$ US $\$ 400,000$ with a per sample cost of around US $\$ 400$, making it an expensive option for RLS. All other NGS methods for HIVDR genotyping are based on in-house assays developed to the convenience of the laboratories running the assays. However, most of these in-house assays are labor intensive and require additional quality control measures to lessen the effect of sequencing errors generated by NGS technologies. Figure 1 summarizes the Sanger and NGS workflows from sample to producing a report. 
Table 2. In-house HIVDR genotyping assays for use in resource limited settings.

\begin{tabular}{|c|c|c|c|c|c|c|}
\hline Year & Source & Country & Specimen Type & V1 Threshold & HIV-1 Gene & PMID \\
\hline 2006 & Steegan K et al. [32] & Belgium & Plasma & $\geq 500 \mathrm{cp} / \mathrm{mL}$ & PR, RT & 16375980 \\
\hline 2007 & Chen JHK et al. [33] & China & Plasma & $\geq 400 \mathrm{cp} / \mathrm{mL}$ & PR, RT & 17449318 \\
\hline 2008 & Van Laethem K et al. [34] & Belgium & Plasma & NS & IN & 18706932 \\
\hline 2008 & Pillay V et al. [35] & South Africa & Plasma & NS & PR, RT & 18575198 \\
\hline 2009 & Hearps AC et al. [36] & Australia & Plasma & $>50 \mathrm{cp} / \mathrm{mL}$ & IN & 19917199 \\
\hline 2009 & Saravanan et al. [37] & India & Plasma & $>1500 \mathrm{cp} / \mathrm{mL}$ & PR, RT & 19490976 \\
\hline 2010 & Wallis CL et al. [38] & South Africa & Plasma & $>1000 \mathrm{cp} / \mathrm{mL}$ & PR, RT & 19917318 \\
\hline 2010 & Yang C et al. [39] & USA & DBS & $<400 \mathrm{cp} / \mathrm{mL}$ & PR, RT & 20660209 \\
\hline 2011 & Zhou Z et al. [30] & USA & Plasma and DBS & $<400 \mathrm{cp} / \mathrm{mL}$ & PR, RT & 22132237 \\
\hline 2011 & Fokam J et al. [40] & Cameroon & Plasma & $>1000 \mathrm{cp} / \mathrm{mL}$ & PR, RT & 21465085 \\
\hline 2012 & Chen JHK et al. [41] & Hong Kong & Plasma & $\geq 400 \mathrm{cp} / \mathrm{mL}$ & PR, RT & 22302906 \\
\hline 2012 & Parkin N et al. [42] & USA & DBS & $\geq 1000 \mathrm{cp} / \mathrm{mL}$ & PR, RT & 22544187 \\
\hline 2013 & To SWC et al. [8] & Hong Kong & Plasma & $\geq 1000 \mathrm{cp} / \mathrm{mL}$ & IN & 23886504 \\
\hline 2013 & Charturbhuj DN et al. [43] & India & Plasma & $\geq 1000 \mathrm{cp} / \mathrm{mL}$ & PR, RT & 23353551 \\
\hline 2013 & Aitken SC et al. [44] & Netherlands & Plasma and DBS & $\geq 1000 \mathrm{cp} / \mathrm{mL}$ & PR, RT & 23536405 \\
\hline 2013 & Inzaule S et al. [24] & Kenya & Plasma and DBS & $\geq 1000 \mathrm{cp} / \mathrm{mL}$ & PR, RT & 23224100 \\
\hline 2014 & Acharya A et al. [45] & India & Plasma & $\geq 1000 \mathrm{cp} / \mathrm{mL}$ & PR, RT & 25157501 \\
\hline 2014 & Manasa J et al. [29] & South Africa & Plasma & $\geq 1000 \mathrm{cp} / \mathrm{mL}$ & PR, RT & 24747156 \\
\hline 2014 & Chaturbhuj DN et al. [43] & India & Plasma & $>1000 \mathrm{cp} / \mathrm{mL}$ & PR, RT & 24533056 \\
\hline 2015 & Armenia D et al. [46] & Italy & Plasma & $>50 \mathrm{cp} / \mathrm{mL}$ & IN & 25712318 \\
\hline 2017 & Gupta S et al. [47] & Canada & Plasma & $>100 \mathrm{cp} / \mathrm{mL}$ & PR, RT & 28473986 \\
\hline 2019 & Seatla KK et al. [48] & Botswana & Plasma & $>1000 \mathrm{cp} / \mathrm{mL}$ & IN & 31751353 \\
\hline 2020 & Chrysostomou AC et al. [49] & Cyprus & Plasma & $\geq 1000 \mathrm{cp} / \mathrm{mL}$ & PR, RT, IN & 32061896 \\
\hline
\end{tabular}

$\mathrm{cp} / \mathrm{mL}$, copies per microliter; DBS, dried blood spots; IN, integrase; NS, not stated; PR, Protease; RT, reverse transcriptase; SA, South Africa; VL, viral load.

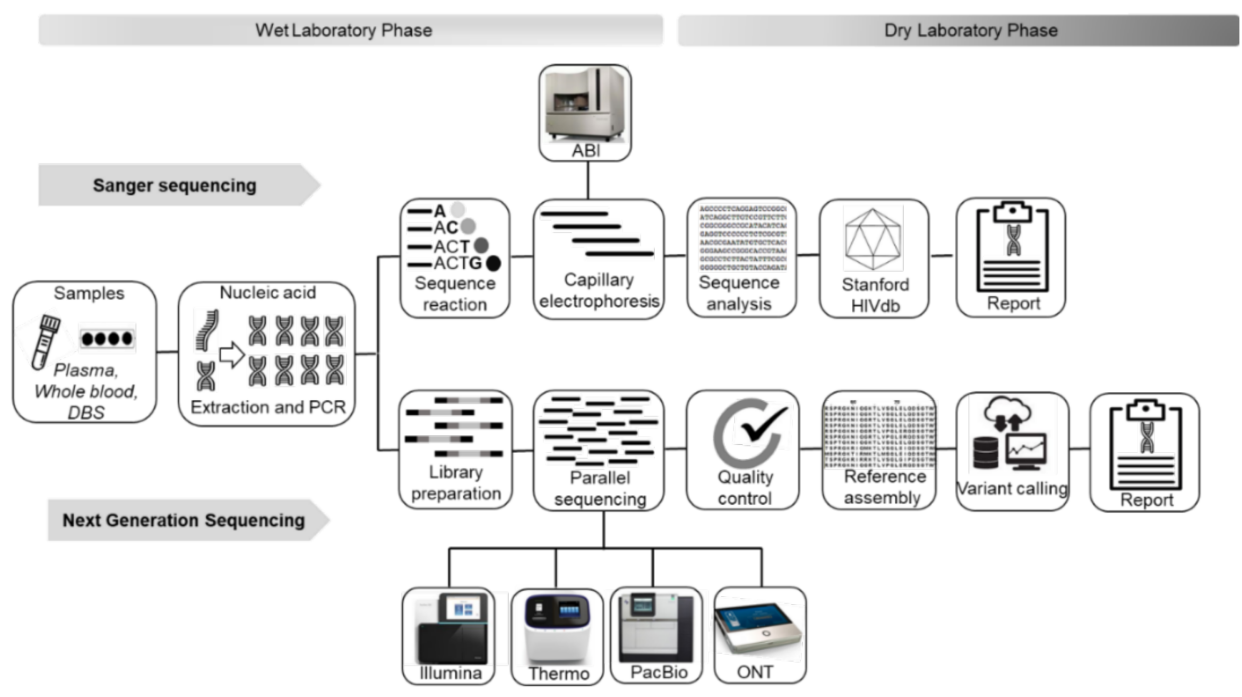

Figure 1. Summary comparison of Sanger sequencing and NGS HIVDR workflows.ABI, Applied Biosystems; DBS, dried blood spots; HIV db, HIV drug resistance database; ONT, Oxford Nanopore Technology; PacBio, Pacific Biosciences; PCR, polymerase chain reaction; Thermo, Thermo Fisher.

\section{Advantages and Disadvantages of Sequencing Methods for HIVDR Genotyping}

For over two decades Sanger sequencing has been shown to be a highly reproducible and interpretable method for diagnosing HIVDR in clinical settings [14,32,33]. This is because Sanger sequencing has been available long enough for use in HIVDR genotyping, producing high quality sequence data, with short turnaround times, and relatively simple workflows and data interpretation [14]. However, in addition to the inability of Sanger sequencing to reliably detect LA-DRVs [19,52], it has limited data throughput [53]. 
Also, there is less flexibility in choice of sequencing platforms, which is mainly limited to one manufacturer (i.e., Thermo Fisher). Moreover, Sanger sequencing requires standard molecular biology workflows and infrastructure which are mostly available in centralized laboratories in RLS [14]. This reduces its accessibility and affordability for HIVDR genotyping in RLS; hence, its preferred for use only after second-line ART failure [54].

In contrast, there is a wider range of NGS platforms supplied by various manufacturers, using different sequencing chemistries (Table 1) and achieving massive parallel sequencing [8]. This offers laboratories flexibility in choosing which assays to run but poses a challenge in reproducibility across various platforms. However, there is lack of validated NGS methods for clinical use, which is compounded by high sequencing errors and workflows that are labor intensive. NGS methods also require high infrastructure costs and high levels of expertise [14]. In addition, long-term investment in remote and/or cloud-based servers is required to keep up with the large amounts of data generated by NGS. The vast amounts of data also pose challenges in data analysis [55]. Individual laboratories often develop their own data analysis pipelines, making it difficult to normalize data quality across the board. Table 3 summarizes the strengths and weaknesses of Sanger sequencing and NGS in relation to their use in HIVDR genotyping [14].

Table 3. Strengths and limitations of Sanger sequencing and NGS in HIVDR genotyping methods.

\begin{tabular}{|c|c|c|}
\hline & Strengths & Weaknesses \\
\hline Sanger sequencing & $\begin{array}{ll}\text { - } & \text { Several validated methods for } \\
\text { clinical use } \\
\text { - } & \text { Low sequencing errors } \\
\text { - } & \text { Relatively simple workflows and data } \\
\text { analysis } \\
\text { - } \quad \text { Relatively shorter turnaround times } \\
\text { - } \quad \text { Common method in RLS } \\
\text { Easily accessible software for } \\
\text { interpretation (such as Stanford HIVdb) }\end{array}$ & $\begin{array}{l}\text { - } \quad \text { High cost per test } \\
\text { - } \quad \text { Cannot reliably detect LA-DRVs } \\
\text { - } \quad \text { Not suitable for sequencing long genes/large } \\
\text { - } \quad \text { Nenomes } \\
\text { - } \quad \text { High infrastructure costs } \\
\text { - } \quad \text { Require standard molecular biology workflows }\end{array}$ \\
\hline $\begin{array}{l}\text { Next generation } \\
\text { sequencing }\end{array}$ & $\begin{array}{l}\text { - } \quad \text { Lower cost per test through pooling } \\
\text { - } \quad \text { High sensitivity for LA-DRVs } \\
\text { - } \quad \text { Suitable for sequencing long } \\
\text { genes/large genomes } \\
\text { - } \quad \text { Massive parallel sequencing }\end{array}$ & $\begin{array}{ll}\text { - } & \text { Only one validated method for clinical use } \\
\text { - } & \text { High sequencing errors } \\
\text { - } & \text { Complex labor-intensive workflows and } \\
\text { data analysis } \\
\text { - } & \text { Longer turnaround time } \\
\text { - } & \text { High infrastructure costs } \\
\text { - } & \text { Nequires specialized facilities } \\
\text { - } & \text { Can produce unequal sequencing coverage } \\
\text { - } & \text { Software for interpretation depend on data } \\
\text { - } & \text { output files } \\
\text { - } & \text { Requires personnel with high-level expertise } \\
& \text { Require standard molecular biology workflows }\end{array}$ \\
\hline
\end{tabular}

RLS, resource limited settings; DBS, dried blood spots; LA-DRV, low-abundance drug-resistant variants. This table was adapted from the following reference [14].

\section{Future Recommendations for HIVDR Genotyping and Knowledge Gaps}

As new drugs to treat HIV-1 patients increase and extensive drug class resistance grows, HIVDR genotyping methods need to evolve to determine resistance to newer drug classes such as capsid inhibitors, entry inhibitors, nucleoside analogue reverse transcriptase translocation inhibitors and Rev inhibitors. For instance, as ART programs in RLS adopt use of integrase strand transfer inhibitors such as dolutegravir and possibly the long-acting injectable cabotegravir, sequencing of longer reads that cover all relevant HIV-1 viral genes (i.e., PR, RT, and IN) is required. Combined PCR amplification of these genes is difficult as 
they are spread apart. Genotyping PR and RT genes in a separate assay to the IN gene is an option; however, this doubles the HIVDR genotyping workload. Therefore, there is a need to design Sanger sequencing assays that detect all relevant mutations in a single amplicon, in order to simplify HIVDR genotyping for clinical diagnostics and research use in RLS.

Although there are several advantages of Sanger sequencing over NGS for clinical diagnostic use, further technical innovations are still required to make Sanger sequencing affordable and available in RLS. The high cost per sample remains a major drawback for implementation of HIVDR genotyping in RLS. NGS can reduce the per sample costs through sample pooling which, however, results in longer turnaround times. Centralizing NGS for HIVDR genotyping could help address the challenge of longer turnaround times and higher per sample costs. Subsidizing of instrument and consumable costs by manufacturers for RLS, together with governmental support will also go a long way in reducing costs and establishing NGS in RLS.

Requirements for expert bioinformatics analyses and high sequencing errors also remain major barriers for use of NGS in HIVDR genotyping. There is a need for international standards that guide NGS for HIVDR genotyping, as well as standardized data analysis pipelines to ensure reproducible, accurate and high-quality data outputs. This could be achieved through internal and external quality assurance programs [11], and validating in-house assays against those that are FDA approved, such as the Sentosa SQ HIV-1 Genotyping Assay. Moreover, validation of commonly used data analysis pipelines for HIVDR mutation calling, such as HyDRA, PASeq and MiCall, is required to address challenges with bioinformatics and data quality [12]. These data analysis pipelines commonly comprise filtering of low-quality data, detection and quantification of amino acid variants at known mutation positions.

HyDRA, PASeq and MiCall are freely available web-based data analysis pipelines that require only minimal bioinformatics expertise and infrastructure [55]. They all use the Stanford HIV drug resistance database (Stanford HIVdb) algorithm, allowing for easy HIV resistance interpretation [21]. HyDRA is compatible with both Illumina and Ion torrent sequencing data and it uses quality control and sequencing error models for data quality assurance [21]. Unlike HyDRA, PASeq is compatible with only Illumina sequencing data. It uses quality control, contamination control and APOBEC hypermutation detection for data quality assurance [21]. Similar to PASeq, MiCall is only compatible with Illumina sequencing data. It uses quality control and sequencing error models for data quality assurance [21]. Despite the minor differences in procedures for data processing and reporting, these analysis pipelines have shown comparable HIV resistance interpretation with less bias for variants at $\geq 5 \%$ threshold, although the clinical relevance of LADRVs (i.e., including those at $\geq 5 \%-<20 \%$ thresholds) require further investigations [21,55]. Therefore, these data analysis pipelines can drastically reduce quality control problems associated with NGS and have potential to produce consistent HIV resistance data that is easily and rapidly interpreted to inform clinical decisions.

In addition, understanding the clinical relevance of LA-DRVs detected by NGS remains elusive for use of NGS data in HIV-1 treatment clinical decisions [6]. The Sentosa HIV-1 Genotyping Assay detects up to 10\% variant threshold, but the decision on which threshold accurately predicts treatment response is yet to be made, and requires international efforts [12]. As NGS platforms continue to improve with reduced sequencing error rates, the ability to sequence multiple samples in a single sequencing run and possibly automating data analysis will make NGS more feasible, accessible and affordable for HIVDR genotyping in RLS [21].

\section{Conclusions}

HIVDR remains the greatest barrier to sustainable viral suppression on ART, whilst cost remains the greatest barrier to HIVDR genotyping in RLS. Available in-house and commercial sequencing assays should aim to offer accessible and relevant cost-effective HIVDR genotyping that can be used to make clinical decisions. In this review, we emphasize 
the need for Sanger sequencing assays to adapt to dynamic HIV-1 treatment programs, to simplify and make HIVDR genotyping affordable. We also highlight that NGS has great potential to achieve low-cost HIVDR genotyping useful for individual and diagnostic publichealth use in RLS. Moreover, validation of wet-lab processes and data analysis pipelines is required for optimal detection and consistent interpretation of HIV resistance data for clinical utility. Ultimately, firm commitments and partnerships between the molecular diagnostics industry, local governments in RLS and global health agencies, are required to overcome HIVDR genotyping barriers that have often slowed down efforts by the UNAIDS to end the HIV epidemic [55].

Author Contributions: Conceptualization, S.M. and B.C.; investigation, S.M.; resources, B.C.; writing—original draft preparation, S.M.; writing—review and editing, L.G., M.P., J.M., K.N. and B.C. visualization, S.M. and B.C.; supervision, B.C.; project administration, S.M.; funding acquisition, B.C. All authors have read and agreed to the published version of the manuscript.

Funding: We acknowledge support from the European and Developing Countries Clinical Trials Partnership (EDCTP) Career Development Fellowship (Grant number: TMA2019CDF- 2728), the Poliomyelitis Research Foundation (Grant number: 21/36), the Centre for AIDS Programme Research in South Africa (CAPRISA) and the Department of Virology at the University of KwaZulu-Natal and National Health Laboratory Service.

Institutional Review Board Statement: S.M. study is given a provisional approval by the Biomedical Research Ethics Committee of the University of KwaZulu-Natal, School of Laboratory Medicine and Medical Science: Project number: BREC/000026/2021.

Informed Consent Statement: Not applicable.

Data Availability Statement: Not applicable.

Conflicts of Interest: The authors declare that they have no competing interests.

\section{References}

1. UNIADS. Understanding Fast-Track Targets. Accelerating Action to End the AIDS Epidemic by 2030. Available online: https: / / www.unaids.org/sites/default/files/media_asset/201506_JC2743_Understanding_FastTrack_en.pdf (accessed on 24 May 2021).

2. Lima, V.D.; St-Jean, M.; Rozada, I.; Shoveller, J.A.; Nosyk, B.; Hogg, R.S.; Sereda, P.; Barrios, R.; Montaner, J.S.G. Progress towards the United Nations 90-90-90 and 95-95-95 targets: The experience in British Columbia, Canada. J. Int. AIDS Soc. 2017, 20 , e25011. [CrossRef]

3. Takou, D.; Fokam, J.; Teto, G.; Santoro, M.-M.; Ceccherini-Silberstein, F.; Nanfack, A.J.; Sosso, S.M.; Dambaya, B.; Salpini, R.; Billong, S.C.; et al. HIV-1 drug resistance testing is essential for heavily-treated patients switching from first- to second-line regimens in resource-limited settings: Evidence from routine clinical practice in Cameroon. BMC Infect. Dis. 2019, 19, 246. [CrossRef] [PubMed]

4. Wu, S.; Sandstrom, P.; Ji, H. Development and application of performance sequencing-based HIV drug resistance assays. Viruses 2020, 12, 627.

5. Günthard, H.F.; Calvez, V.; Paredes, R.; Pillay, D.; Shafer, R.W.; Wensing, A.M.; Jacobsen, D.M.; Richman, D.D. Human immunodeficiency virus drug resistance: 2018 recommendations of the international antiviral society-USA panel. Clin. Infect. Dis. 2019, 68, 177-187. [CrossRef] [PubMed]

6. Mbunkah, H.A.; Bertagnolio, S.; Hamers, R.L.; Hunt, G.; Inzaule, S.; Rinke De Wit, T.F.; Paredes, R.; Parkin, N.T.; Jordan, M.R.; Metzner, K.J. Low-abundance drug-resistant HIV-1 variants in antiretroviral drug-naive individuals: A systematic review of detection methods, prevalence, and clinical impact. J. Infect. Dis. 2020, 221, 1584-1597. [CrossRef]

7. Stranneheim, H.; Lundeberg, J. Stepping stones in DNA sequencing. Biotechnol. J. 2012, 7, 1063-1073. [CrossRef]

8. To, S.W.C.; Chen, J.H.K.; Wong, K.H.; Chan, K.C.W.; Ng, H.M.; Wu, H.; Lam, J.T.; Yam, W.C. Performance comparison of an in-house integrase genotyping assay versus the ViroSeq Integra48, and study of HIV-1 integrase polymorphisms in Hong Kong. J. Clin. Virol. 2013, 58, 299-302. [CrossRef]

9. Tekin, D.; Gokengin, D.; Onay, H.; Erensoy, S.; Sertoz, R. Investigation of drug resistance against protease, reverse transcriptase, and integrase inhibitors by next-generation sequencing in HIV-positive patients. J. Med. Virol. 2020, 93, 3627-3633. [CrossRef] [PubMed]

10. Silver, N.; Paynter, M.; McAllister, G.; Atchley, M.; Sayir, C.; Short, J.; Winner, D.; Alouani, D.J.; Sharkey, F.H.; Bergefall, K.; et al. Characterization of minority HIV-1 drug resistant variants in the United Kingdom following the verification of a deep sequencing-based HIV-1 genotyping and tropism assay. AIDS Res. Ther. 2018, 15, 1-18. [CrossRef] 
11. Lee, E.R.; Gao, F.; Sandstrom, P.; Ji, H. External quality assessment for next-generation sequencing-based HIV drug resistance testing: Unique requirements and challenges. Viruses 2020, 12, 550. [CrossRef]

12. Ji, H.; Sandstrom, P.; Paredes, R.; Harrigan, P.R.; Brumme, C.J.; Rios, S.A.; Noguera-Julian, M.; Parkin, N. Are we ready for NGS HIV drug resistance testing? The second "Winnipeg consensus" symposium. Viruses 2020, 12, 586. [CrossRef] [PubMed]

13. Boucher, C.A.; Bobkova, M.R.; Geretti, A.M.; Hung, C.; Kaiser, R. State of the art in HIV drug resistance: Science and technology knowledge gap. AIDS Rev. 2018, 20, 26-41.

14. Inzaule, S.C.; Ondoa, P.; Peter, T.; Mugyenyi, P.N.; Stevens, W.S.; de Wit, T.F.R.; Hamers, R.L. Affordable HIV drug-resistance testing for monitoring of antiretroviral therapy in sub-Saharan Africa. Lancet Infect. Dis. 2016, 16, e267-e275. [CrossRef]

15. Parikh, U.M.; McCormick, K.; Van Zyl, G.; Mellors, J.W. Future technologies for monitoring HIV drug resistance and cure. Curr. Opin. HIV AIDS 2017, 12, 182-189. [CrossRef] [PubMed]

16. Applied Biosystems. The Seq Studio Genetic Analyzer Simplifies the Analysis of Triplet Repeat Expansion with Amplidex PCR/CE Reagents. Available online: https://assets.thermofisher.com/TFS-Assets/CSD/Reference-Materials/whitepaperasuragen-seqstudio-genetic-analyzer-triplet-repeats.pdf\%0A (accessed on 25 March 2021).

17. Liu, L.; Li, Y.; Li, S.; Hu, N.; He, Y.; Pong, R.; Lin, D.; Lu, L.; Law, M. Comparison of next-generation sequencing systems. J. Biomed. Biotechnol. 2012, 2012,1-11. [CrossRef] [PubMed]

18. Kchouk, M.; Gibrat, J.F.; Elloumi, M. Generations of sequencing technologies: From first to next generation. Biol. Med. 2017, 9, 1-8. [CrossRef]

19. Ávila-Ríos, S.; Parkin, N.; Swanstrom, R.; Paredes, R.; Shafer, R.; Ji, H.; Kantor, R. Next-generation sequencing for HIV drug resistance testing: Laboratory, clinical, and implementation considerations. Viruses 2020, 12, 617. [CrossRef] [PubMed]

20. Maljkovic Berry, I.; Melendrez, M.C.; Bishop-Lilly, K.A.; Rutvisuttinunt, W.; Pollett, S.; Talundzic, E.; Morton, L.; Jarman, R.G. Next generation sequencing and bioinformatics methodologies for infectious disease research and public health: Approaches, applications, and considerations for development of laboratory capacity. J. Infect. Dis. 2020, 221, S292-S307. [CrossRef] [PubMed]

21. Ji, H.; Enns, E.; Brumme, C.J.; Parkin, N.; Howison, M.; Lee, E.R.; Capina, R.; Marinier, E.; Avila-Rios, S.; Sandstrom, P.; et al. Bioinformatic data processing pipelines in support of next-generation sequencing-based HIV drug resistance testing: The Winnipeg consensus. J. Int. AIDS Soc. 2018, 21, 1-14. [CrossRef] [PubMed]

22. WHO. The Use of Next-Generation Sequencing Technologies for the Detection of Mutations Associated with Drug Resistance in Mycobacterium Tuberculosis Complex: Technical Guide WHO. Available online: https://apps.who.int/iris/handle/10665/2744 (accessed on 1 February 2021).

23. Emmadi, R.; Boonyaratanakornkit, J.B.; Selvarangan, R.; Shyamala, V.; Zimmer, B.L.; Williams, L.; Bryant, B.; Schutzbank, T.; Schoonmaker, M.M.; Amos Wilson, J.A.; et al. Molecular methods and platforms for infectious diseases testing a review of FDA-approved and cleared assays. J. Mol. Diagn. 2011, 13, 583-604. [CrossRef]

24. Inzaule, S.; Yang, C.; Kasembeli, A.; Nafisa, L.; Okonji, J.; Oyaro, B.; Lando, R.; Mills, L.A.; Laserson, K.; Thomas, T.; et al. Field evaluation of a broadly sensitive HIV-1 In-house genotyping assay for use with both plasma and dried blood spot specimens in a resource-limited country. J. Clin. Microbiol. 2013, 51, 529-539. [CrossRef] [PubMed]

25. Xu, S.; Zhong, P.; Li, J.; Song, A.; Li, H.; Nie, J.; Li, X.; Wang, Y. Comparative evaluation of the ViroSeq HIV-1 genotyping system and an in-house method for analysis of HIV-1 drug-resistance mutations in China. Mol. Diagnosis Ther. 2011, 15, 41-52. [CrossRef] [PubMed]

26. Rosemary, A.; Chika, O.; Jonathan, O.; Godwin, I.; Georgina, O.; Azuka, O.; Zaidat, M.; Philippe, C.; Oliver, E.; Oche, A.; et al. Genotyping performance evaluation of commercially available HIV-1 drug resistance test. PLoS ONE 2018, 13, e0198246. [CrossRef]

27. Gachogo, R.W.; Mwai, D.N.; Onyambu, F.G. Cost analysis of implementing HIV drug resistance testing in Kenya: A case study of a service delivery site at a tertiary level hospital in Kenya. F1000Research 2020, 9, 793. [CrossRef]

28. Magomere, E.O.; Nyangahu, D.D.; Kimoloi, S.; Webala, B.A.; Ondigo, B.N. Performance characteristics of a modified HIV-1 drug resistance genotyping method for use in resource-limited settings. F1000Research 2019, 8, 1518. [CrossRef] [PubMed]

29. Manasa, J.; Danaviah, S.; Pillay, S.; Padayachee, P.; Mthiyane, H.; Mkhize, C.; Lessells, R.J.; Seebregts, C.; de Wit, T.F.R.; Viljoen, J.; et al. An affordable HIV-1 drug resistance monitoring method for resource limited settings. JoVE 2014, 85, e51242. [CrossRef] [PubMed]

30. Zhou, Z.; Wagar, N.; DeVos, J.R.; Rottinghaus, E.; Diallo, K.; Nguyen, D.B.; Bassey, O.; Ugbena, R.; Wadonda-Kabondo, N.; McConnell, M.S.; et al. Optimization of a low cost and broadly sensitive genotyping assay for HIV-1 drug resistance surveillance and monitoring in resource-limited settings. PLoS ONE 2011, 6, e28184. [CrossRef] [PubMed]

31. Bioafrica. SATuRN and Life Technologies (ABI) Partnership Provide a Discounted HIV Resistance Genotyping System. Available online: https: / / www.krisp.org.za / report.php?id=8 (accessed on 26 May 2021).

32. Steegen, K.; Demecheleer, E.; De Cabooter, N.; Nges, D.; Temmerman, M.; Ndumbe, P.; Mandaliya, K.; Plum, J.; Verhofstede, C. A sensitive in-house RT-PCR genotyping system for combined detection of plasma HIV-1 and assessment of drug resistance. J. Virol. Methods 2006, 133, 137-145. [CrossRef]

33. Chen, J.H.K.; Wong, K.H.; Chan, K.; Lam, H.Y.; Lee, S.S.; Li, P.; Lee, M.P.; Tsang, D.N.; Zheng, B.J.; Yuen, K.Y.; et al. Evaluation of an in-house genotyping resistance test for HIV-1 drug resistance interpretation and genotyping. J. Clin. Virol. 2007, 39, 125-131. [CrossRef] [PubMed] 
34. Van Laethem, K.; Schrooten, Y.; Covens, K.; Dekeersmaeker, N.; De Munter, P.; Van Wijngaerden, E.; Van Ranst, M.; Vandamme, A.M. A genotypic assay for the amplification and sequencing of integrase from diverse HIV-1 group M subtypes. J. Virol. Methods 2008, 153, 176-181. [CrossRef]

35. Pillay, V.; Ledwaba, J.; Hunt, G.; Rakgotho, M.; Singh, B.; Makubalo, L.; Bennett, D.E.; Puren, A.; Morris, L. Antiretroviral drug resistance surveillance among drug-naive HIV-1-infected individuals in Gauteng Province, South Africa in 2002 and 2004 . Antivir Ther. 2008, 13, 101-107. [PubMed]

36. Hearps, A.C.; Greengrass, V.; Hoy, J.; Crowe, S.M. An HIV-1 integrase genotype assay for the detection of drug resistance mutations. Sex. Health 2009, 6, 305-309. [CrossRef] [PubMed]

37. Saravanan, S.; Vidya, M.; Balakrishnan, P.; Kumarasamy, N.; Solomon, S.S.; Solomon, S.; Kantor, R.; Katzenstein, D.; Ramratnam, B.; Mayer, K.H. Evaluation of two human immunodeficiency virus-1 genotyping systems: ViroSeq 2.0 and an in-house method. J. Virol. Methods 2009, 159, 211-216. [CrossRef] [PubMed]

38. Wallis, C.L.; Papathanasopoulos, M.A.; Lakhi, S.; Karita, E.; Kamali, A.; Kaleebu, P.; Sanders, E.; Anzala, O.; Bekker, L.-G.; Stevens, G.; et al. Affordable in-house antiretroviral drug resistance assay with good performance in non-subtype B HIV-1. J. Virol. Methods 2010, 163, 505-508. [CrossRef]

39. Inzaule, S.C.; Ondoa, P.; Peter, T.; Mugyenyi, P.N.; Stevens, W.S.; de Wit, T.F.R.; Hamers, R.L.; Ji, H.; Enns, E.; Brumme, C.J.; et al. Development and application of performance sequencing-based HIV drug resistance assays. J. Int. AIDS Soc. 2020, 20, 1-10.

40. Fokam, J.; Salpini, R.; Santoro, M.M.; Cento, V.; D’Arrigo, R.; Gori, C.; Perno, C.F.; Colizzi, V.; Nanfack, A.; Gwom, L.C.; et al. Performance evaluation of an in-house human immunodeficiency virus type-1 protease-reverse transcriptase genotyping assay in Cameroon. Arch. Virol. 2011, 156, 1235-1243. [CrossRef]

41. Chen, J.H.K.; Wong, K.H.; Li, P.C.K.; Chan, K.K.C.; Lee, M.P.; To, S.W.C.; Yam, W.C. In-house human immunodeficiency virus-1 genotype resistance testing to determine highly active antiretroviral therapy resistance mutations in Hong Kong. Hong Kong Med. J. 2012, 18, 20-24. [PubMed]

42. Parkin, N.; De Mendoza, C.; Schuurman, R.; Jennings, C.; Bremer, J.; Jordan, M.R.; Bertagnolio, S.; Brooks, J.; Sandstrom, P.; Wagar, N.; et al. Evaluation of in-house genotyping assay performance using dried blood spot specimens in the global world health organization laboratory network. Clin. Infect. Dis. 2012, 54, S273-S279. [CrossRef] [PubMed]

43. Chaturbhuj, D.N.; Nirmalkar, A.P.; Paranjape, R.S.; Tripathy, S.P. Evaluation of a cost effective in-house method for HIV-1 drug resistance genotyping using plasma samples. PLoS ONE 2014, 9, e87441. [CrossRef]

44. Aitken, S.C.; Bronze, M.; Wallis, C.L.; Stuyver, L.; Steegen, K.; Balinda, S.; Kityo, C.; Stevens, W.; Rinke De Wit, T.F.; Schuurman, R. A pragmatic approach to HIV-1 drug resistance determination in resource-limited settings by use of a novel genotyping assay targeting the reverse transcriptase-encoding region only. J. Clin. Microbiol. 2013, 51, 1757-1761. [CrossRef]

45. Acharya, A.; Vaniawala, S.; Shah, P.; Misra, R.N.; Wani, M.; Mukhopadhyaya, P.N. Development, validation and clinical evaluation of a low cost in-house HIV-1 drug resistance genotyping assay for Indian patients. PLoS ONE 2014, 9, e105790. [CrossRef] [PubMed]

46. Armenia, D.; Fabeni, L.; Alteri, C.; Di Pinto, D.; Di Carlo, D.; Bertoli, A.; Gori, C.; Carta, S.; Fedele, V.; Forbici, F.; et al. HIV-1 integrase genotyping is reliable and reproducible for routine clinical detection of integrase resistance mutations even in patients with low-level viraemia. J. Antimicrob. Chemother. 2014, 70, 1865-1873. [CrossRef] [PubMed]

47. Gupta, S.; Taylor, T.; Patterson, A.; Liang, B.; Bullard, J.; Sandstrom, P.; Van Domselaar, G.; Ji, H. A robust PCR protocol for HIV drug resistance testing on low-level viremia samples. BioMed Res. Int. 2017, 2017, 4979252. [CrossRef]

48. Seatla, K.K.; Choga, W.T.; Mogwele, M.; Diphoko, T.; Maruapula, D.; Mupfumi, L.; Musonda, R.M.; Rowley, C.F.; Avalos, A.; Kasvosve, I.; et al. Comparison of an in-house 'home-brew' and commercial ViroSeq integrase genotyping assays on HIV-1 subtype C samples. PLoS ONE 2019, 14, e0224292. [CrossRef]

49. Chrysostomou, A.C.; Topcu, C.; Stylianou, D.C.; Hezka, J.; Kostrikis, L.G. Development of a new comprehensive HIV-1 genotypic drug resistance assay for all commercially available reverse transcriptase, protease and integrase inhibitors in patients infected with group M HIV-1 strains. Infect. Genet. Evol. 2020, 81, 104243. [CrossRef] [PubMed]

50. Capina, R.; Li, K.; Kearney, L.; Vandamme, A.; Harrigan, P.R.; Laethem, K. Van. Quality control of next-generation sequencingbased HIV-1 drug resistance data in clinical laboratory information systems framework. Viruses 2020, 12, 645. [CrossRef]

51. Dessilly, G.; Goeminne, L.; Vandenbroucke, A.T.; Dufrasne, F.E.; Martin, A.; Kabamba-Mukabi, B. First evaluation of the nextgeneration sequencing platform for the detection of HIV-1 drug resistance mutations in Belgium. PLoS ONE 2018, 13 , e0209561. [CrossRef] [PubMed]

52. Lee, E.R.; Parkin, N.; Jennings, C.; Brumme, C.J.; Enns, E.; Casa, M.; Howison, M.; Coetzer, M.; Avila-rios, S.; Capina, R. Performance comparison of next generation sequencing analysis pipelines for HIV-1 drug resistance testing. Sci. Rep. 2020, 10, 1-10. [CrossRef] [PubMed]

53. Taylor, T.; Lee, E.R.; Nykoluk, M.; Enns, E.; Liang, B.; Capina, R.; Gauthier, M.K.; Van Domselaar, G.; Sandstrom, P.; Brooks, J.; et al. A MiSeq-HyDRA platform for enhanced HIV drug resistance genotyping and surveillance. Sci. Rep. 2019, 9, 1-11. [CrossRef]

54. Inzaule, S.C.; Hamers, R.L.; Paredes, R.; Yang, C.; Schuurman, R.; de Wit, T.F.R. The evolving landscape of HIV drug resistance diagnostics for expanding testing in resource-limited settings. AIDS Rev. 2017, 19, 179-189.

55. Noguera-Julian, M.; Edgil, D.; Harrigan, P.R.; Sandstrom, P.; Godfrey, C.; Paredes, R. Next-generation human immunodeficiency virus sequencing for patient management and drug resistance surveillance. J. Infect. Dis. 2017, 216, 829-833. [CrossRef] [PubMed] 